\title{
Motivations, Concerns, and Expectations of Scandinavian Health Professionals Volunteering for Humanitarian Assignments
}

Magdalena Bjerneld, RNT, MLic, Gunilla Lindmark, MD, PhD, Lucia Ann McSpadden, PhD, and Martha J. Garrett, PhD

International nongovernmental organizations (NGOs) involved in humanitarian assistance employ millions of volunteers. One of the major challenges for the organizations is the high turnover rate among their personnel. Another is recruiting the right persons. As part of a series of studies investigating factors that affect the recruitment process and the success of assignment, this qualitative study examined health professionals' motivations for volunteering, their various concerns, and their expectations about themselves and the organizations for which they would work. The findings from focus group interviews with potential humanitarian volunteers were considered within the framework of Hertzberg's theory of motivations and Maslow's hierarchy of needs.

The study has significant implications for personnel policy and practice in the

humanitarian sector. Recruitment officers should have the self-actualized person, as described by Maslow, in mind when interviewing candidates. This perspective would make it easier for them to understand the candidates' thoughts and concerns and would lead to more effective interventions. Program officers should have satisfiers and dissatisfiers, as identified by Herzberg, in mind when planning programs. The probability that personnel will leave humanitarian work is lower if they perceive working conditions as good.
Magdalena Bjerneld is Coordinator, Centre for Public Health in Humanitarian Assistance (PHHA), International Maternal and Child Health (IMCH), Department of Women's and Children's Health, Uppsala, Sweden. Gunilla Lindmark is Professor of International Maternal and Reproductive Health at the International Maternal and Child Health (IMCH), Department of Women's and Children's Health, Uppsala University, Uppsala, Sweden. Lucia Ann McSpadden is a Senior Advisor at the Pacific School of Religion, Berkeley, Calif. Martha J. Garrett is a Researcher and Teacher at the International Maternal and Child Health
I n 2004, the world experienced a natural disaster of massive proportion, the tsunami that killed approximately 250,000 people and left many others homeless. Following the tsunami, humanitarian organizations received overwhelming personal financial contributions ${ }^{1}$ and were contacted by large numbers of persons volunteering to work in the affected areas. It has been suggested that this enormous solidarity after the tsunami was in part due to the fact that a natural disaster is easier to understand and respond to than are conflict-based disasters that are basically political in nature. However, many people also feel strong sympathy for victims of wars. Consequently they contribute to fund-raising campaigns for refugees and humanitarian relief efforts in war situations, and some persons even volunteer to go on humanitarian assignments in war-torn areas. ${ }^{1}$

International nongovernmental organizations (NGOs) involved in development and humanitarian assistance currently employ about 19 million persons. This number includes both longer-term career em-

One of the major challenges for the NGOs is

the high turnover rate among both the career employees and the volunteers.

ployees and those who volunteer, often at fairly low pay. ${ }^{2}$ One of the major challenges for the NGOs is the high turnover rate among both the career employees and the volunteers, who typically go on just 1 or 2 missions. ${ }^{3-5}$ Another challenge that NGOs face is recruiting the right persons. Because both natural

(IMCH), Department of Women's and Children's Health, Uppsala University, Uppsala, Sweden.

Reprint requests: Magdalena Bjerneld, IMCH, University Hospital, 75185 Uppsala, Sweden; E-mail: Magdalena.Bjerneld@kbh. uu.se

Disaster Manage Response 2006;4:49-58.

$1540-2487 / \$ 32.00$

Copyright (C) 2006 by the Emergency Nurses Association. doi:10.1016/j.dmr.2006.01.002 
and human-made disasters can occur without warning, volunteers often are needed on short notice. If the situation is acute, agencies may have to fill posts with volunteers who are recruited after minimal evaluation, perhaps just a single telephone interview. ${ }^{6}$

International NGOs need to learn how to be more effective at selecting and retaining staff. NGOs can develop organizational procedures and identify personal characteristics that will improve the chance that a volunteer will carry out a successful mission and continue within humanitarian or development work. Unfortunately, research in this area has been very limited. Kealey has done significant work on overseas effectiveness, which he defines as the ability to live and work effectively in the cross-cultural setting of an overseas assignment. ${ }^{7,8}$ Attempts also have been made to gain insight into human resource management in humanitarian assistance through large-scale surveys, but this research has disclosed little about the volunteers themselves. ${ }^{6,9,10} \mathrm{~A}$ few limited studies by Anderson and Moore ${ }^{11}$ and Liao-Troth and Dunn ${ }^{12}$ have looked at motivations among volunteers.

\section{Theoretical Framework}

The factors that motivate human behavior and personal needs have been addressed in several psychosocial theories, such as Maslow's hierarchy of needs, McClelland's theory of needs, Herzberg's theory of satisfiers and dissatisfiers, Vroom's expectancy theory, and Ritchie and Martin's motivation management theory. ${ }^{13}$ Of these theories, we found Maslow's and Herzberg's theories most relevant to analyzing the expectations and concerns of humanitarian volunteers.

\section{Maslow}

Maslow, a psychologist, studied human needs and factors that motivated behaviors. From his studies, Maslow defined a hierarchy of needs. ${ }^{14}$ He theorized that humans have similar needs that they try to satisfy, usually in the same order, and that these needs can be visualized as a pyramid (see Figure 1). At the base of the pyramid are physiologic needs such as food, water, shelter, and sex. These needs are followed by safety, including security, stability, and freedom from fear. The next tier involves social needs-loving, being loved, feeling that one belongs, and not being lonely. Esteem, including self-esteem, is yet higher and involves achievement, mastery, respect, and recognition from others. At the top of the pyramid is selfactualization, fulfillment of one's potential, and the pursuit of inner talents. According to the concept of prepotency, people must have one level satisfied to a substantial degree before they will pursue the next higher need. ${ }^{14-16}$

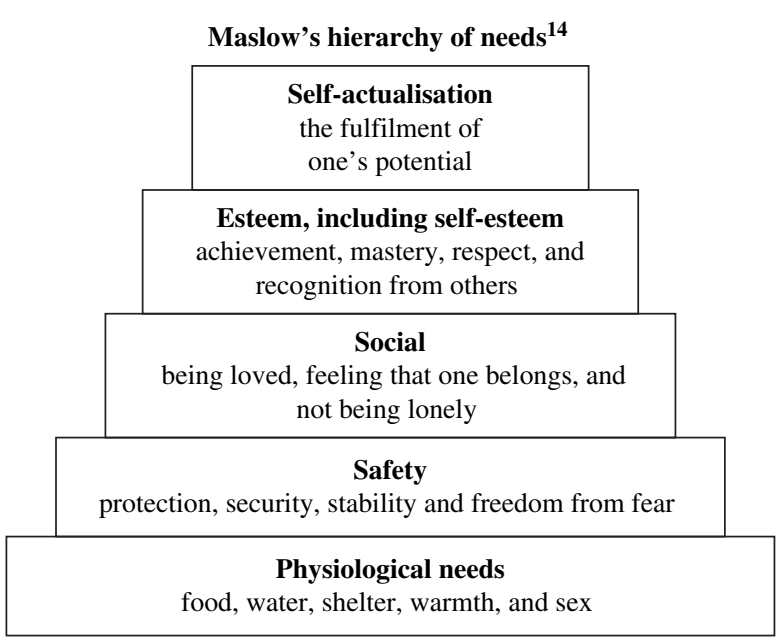

Figure I: Maslow's hierarchy of needs.

\section{Heylighen}

Heylighen ${ }^{15}$ further analyzed Maslow's work. He pointed out that persons who have met the lower needs but have not achieved self-actualization seem to have everything they need. They are secure, have friends and families, are respected, and enjoy high self-esteem. Yet they feel that something is lacking and they experience life as boring and meaningless. It is at this stage that they begin looking for ways to develop fully their own capacities.

\section{Herzberg}

Herzberg ${ }^{17}$ specifically studied job factors that motivate employees. He organized factors that affect how people feel about work into 2 primary groupings (see Table 1).

Satisfiers. Motivation, satisfaction, and long-term positive job performance are determined by 5 factors: achievement, recognition, the work itself, responsibility, and advancement. These factors are called satisfiers and relate directly to what people do in their jobs.

Dissatisfiers. Other factors that do not motivate or create satisfaction are called dissatisfiers because their absence can lead to job dissatisfaction. Dissatisfiers relate to the situation in which work is done and include

\begin{tabular}{|c|c|}
\hline Satisfiers $^{*}$ & Dissatisfiers $^{\dagger}$ \\
\hline Achievements & Company/organization policies \\
\hline Recognition & Supervision \\
\hline The work itself & Interpersonal relation \\
\hline Responsibility & Working conditions \\
\hline Advancement & Salary \\
\hline
\end{tabular}


policy, supervision, interpersonal relations, working conditions, and salary. ${ }^{17}$

\section{Aim of This Study}

The purpose of this study was to shed light on the motivations of volunteers, as well as their concerns and expectations about themselves and the NGOs for which they would work. In a previously reported study, we interviewed 20 Swedish health professionals who had already been out on one or more humanitarian assignments ${ }^{18}$ and analyzed their perceptions of the experiences. The results raised questions about what volunteers are thinking and feeling before they go out on mission. What motivates them to volunteer? What are they expecting?

\section{Method}

A qualitative approach was used to evaluate the motivation, concerns, and expectations of Scandinavian students enrolled in an international health course.

\section{Study Participants}

The study population included 19 Scandinavian health professionals who were attending a 2-month International Health course at Uppsala University, Uppsala, Sweden, during autumn 2003 and spring 2004. These health professionals had no previous experience of humanitarian work abroad. The International Health course has been used as preparatory field training by various NGOs, including the Swedish office of Médecins San Frontièrs (MSF), which has required it for their volunteers. The participants had either decided to volunteer or were giving serious consideration to the possibility and had applied for the course in order to have a chance to be recruited by MSF or another NGO. Some participants already had begun the recruitment and screening process, including information meetings, interviews, and participation in emergency simulations. Although the course participants consisted of both Scandinavian and international students, the study population was limited to Scandinavians because we wanted to link the research to the first study ${ }^{18}$ and because the theoretical framework had a strongly Western perspective.

The course leader described the study to the course participants and asked the Scandinavians if they would be willing to take part in it. They were assured that their participation would be confidential and that all responses would be anonymous. The students had the option to participate or not, as they wished. All but one of the eligible persons offered to participate. The 19 students who agreed to participate were divided into 4 focus groups that consisted of 2 groups of nurses and 2 groups of doctors. One group of nurses was interviewed during autumn 2003, and the other during spring 2004. The 2 groups of doctors were interviewed in spring 2004.

Demographics. The interviewees included 10 nurses (1 man and 9 women) and 9 doctors (3 men and 6 women). Most interviewees were between 25 and 35 years of age. One participant, a female doctor from Denmark, was older than the others. The nurses had basic university education in nursing and at least 2 years of working experience, and some had specialization in an area of nursing. The doctors had completed their basic theoretic training and practical internship and had received their licence to practice as a doctor. The majority had no specialization and only short working experience.

\section{Data Collection Methods}

The focus group interviews, which lasted 1 hour, were led by Magdalena Bjerneld (MB), using an interview guide of semi-structured questions. The guide had been developed by MB and tested on a pilot focus group, and the questions had been deemed appropriate and effective. Some questions referred to the volunteers' motivations, concerns about humanitarian assignments, and expectations about themselves and the NGOs for which they potentially would like to work. Some questions that dealt with specific issues, such as their preparations for work abroad, also elicited responses that revealed a great deal about motivations, concerns, and expectations.

\section{Data Analysis}

The interviews were recorded and transcribed verbatim, resulting in about 100 manuscript pages. Qualitative content analysis was carried out on the transcripts following standard procedures. ${ }^{19}$ All transcripts were read by MB. Meaning units (i.e., phrases or sentences describing or expressing different thoughts or feelings) were copied from the transcripts into a separate file where the text was condensed and coded. Categories and finally themes were then formulated. The last author (M.J. Garrett) read and analyzed the transcripts independently and, after discussion, some modifications were made. Quotations representing major themes and categories were selected and translated from Swedish into English (see Appendix).

\section{Findings}

\section{Qualitative Themes}

The analyzed interviews revealed the following themes among the interviewees' statements. In the 
quotes in the appendix, "D" refers to focus groups with doctors and "N" to focus groups with nurses.

Security. Both nurses and doctors wanted to work for an NGO that was established and had long experience and a good reputation for working in a logical and orderly manner. Both groups were concerned with the stability and functionality of the recruiting organization, but they differed in the thoughts and feelings expressed regarding security.

The nurses were concerned with financial security and physical safety. Nurses believed that going on a mission required having sufficient funds accumulated to cover costs at home while they were away. They believed that the salary paid by the NGOs was too low. They expressed a wish to maintain the kind of life they had achieved before volunteering when they returned from the assignment. This desire meant having assurance that they could find a job when they came back to Sweden so they could pay for their

\section{The nurses were concerned with financial}

\section{security and physical safety.}

apartments and other basic expenses rather than having to move in with relatives. Nurses also were concerned about their physical security during assignments abroad. Some nurses explained that, before attending the International Health course, they had not realized how dangerous it can be to work in humanitarian assistance. They worried about whether the recruiting organizations would take adequate responsibility for them and their safety and if the NGOs would arrange for the nurses to be met when they arrived in the field and would keep track of their movements during the assignment.

The doctors' comments about security were distinctly different. Doctors were concerned that an insecure situation might make them afraid and thus affect their professional performance in the field. The doctors did not express financial worries and were willing to be sent to unstable situations. They had a feeling that things would work out.

Community and coherence. The interviewees realized that their assignments would involve a great deal of teamwork, even more than they were used to within the Swedish health care system. They ex-

\section{Those interviewed also wanted their work to make sense, to be connected in a logical part to a larger whole.}

pressed positive feelings about cooperating as part of a team while on assignment and looked forward to being a part of the humanitarian community even after their return. Those interviewed also wanted their work to make sense, to be connected in a logical part to a larger whole. They wanted to understand their role within a wider context, to see how it related to other work going on within the organization.

During the International Health course, a number of guest lecturers had related cases in which volunteers had had difficulty readjusting when they returned home and felt alienated from their family, friends, and society in general. Some persons had described the experience as a "large black hole." The interviewees expressed fear about experiencing such a sense of alienation. On the other hand, they also were afraid of not returning home, of volunteering over and over again. They did not want to lose their roots or spend their whole lives outside their own country.

Recognition and self-esteem. Some of those interviewed were frustrated by the negative reactions of their own families. They wanted their relatives to recognize and honor their decisions to volunteer and were disappointed when their families responded differently. They also believed that the NGOs recruiting them should recognize and respect their capabilities and make it clear that they were wanted. Such treatment was seen as positive for their own self-esteem. They also hoped that, when they completed their assignments and returned home, their contributions would be understood, recognized, and appreciated by others. They were concerned this would not happen because they had heard that it could be difficult to find someone who was interested in their experiences abroad.

The volunteers felt good about themselves, their professional abilities, and their decision to work for a humanitarian organization. Challenges faced in the field were seen as contributing to higher self-esteem in the future.

Professional competence and mastery. The interviewees expressed many perceptions and feelings about their professional capabilities and their ability to handle their professional responsibilities in the field. The discussions elicited both statements of selfconfidence and self-doubt. Comments revealed acceptance of individual limitations. The volunteers did not believe that they were expected to know everything or to handle every situation on their own. They expected to learn a great deal during the assignment. Even if they felt comfortable with their own professional competence, they recognized that successful field assignments would also require other knowledge, skills, and perspectives that they had not yet acquired. For some participants, this realization had only come during the International Health course.

Wanting to contribute. A major theme in the interviews was a desire to make a contribution to society. Some interviewees identified this desire as a major motivating factor in their decision to volunteer. Altruism (i.e., being concerned about others and 
wanting to work on their behalf) was expressed as a calling and was associated with personal satisfaction. Both doctors and nurses had a desire to make a significant difference. This theme came up in discussions about the type of assignments that they hoped they would be given in the field. Whatever work they were given, they wanted it to mean something. Some participants related that they wanted to work on development projects because they believed that their contributions would be more significant and longerlasting than work in refugee camps and other emergency situations.

The participants were aware that they were very privileged compared with the poor living in low-income countries. Some participants expressed a need to do something to justify their lives and to pay back at least part of what they had just because they were Scandinavian. The concept of heroism (i.e., making contributions that involve bravery or great endurance) also

\section{The concept of heroism (i.e., making contributions that involve bravery or great endurance) also arose during the interviews.}

arose during the interviews. Some participants had been inspired, usually as children, by the doctor-heroes and nurse-heroes they had seen in television dramas or humanitarian documentaries. For some participants, early dreams about playing a hero role had even been a factor in their decision to pursue a career in medicine or nursing. Some persons expressed changes in their original perceptions of heroism. As they became more aware of what heroism involved, they no longer associated it with glamour, fame, and glory. They also realized, largely because of what they had learned in the International Health course, that they were unlikely to be heroes.

Sacrifice was mentioned in connection with making a contribution. Although sacrifice was described as a negative factor that had to be accepted as part of humanitarian assignments, it also was considered as an indicator of the work's importance. Some volunteers expressed that there should be a limit to how much sacrifice should be expected of volunteers.

The search for personal development and selfknowledge. The interviewees expressed a desire for more personal development and had an expectation that experiences abroad would encourage such development. They perceived that opportunities for personal growth were greater under the challenging conditions of a humanitarian assignment than within the routine of the Swedish health care system.

Specifically, volunteers perceived work abroad as an opportunity to test their own limits and were curious about how much they could handle. They wanted challenges such as learning how to provide health care under resource-limited conditions, in other cultures, and even in frightening situations. In this case, fear was seen as a positive influence, not a negative one.

The interviewees had a long-term perspective and saw volunteer assignments as part of their life plans. They wanted to go in the field before they had children and other responsibilities. While some participants perceived volunteer humanitarian work as something that would be limited to a short period of their life, others intended to continue working abroad, often in development work. These individuals saw their first assignment as part of a long commitment that could even involve moving abroad with the families they eventually would have.

The interviewees' responses revealed that they thought a great deal about their own motivations in becoming a volunteer, although this self-questioning did not always lead to answers. They were interested in their own personalities, characters, and limitations. Some participants perceived these characteristics as being basically "set" and wanted to find assignments and organizations that "fit" them. Others saw themselves as "under construction" or believed that they really did not know who they were. These persons hoped that an assignment abroad would help them learn more about themselves. Those who thought they might go on multiple missions said the first mission would help them see where they fit in the overall humanitarian system, what type of work they would most enjoy, and what their "niche" might be.

A search for new experiences. A desire for new personal experiences was another motivating factor. Some of the volunteers wanted to travel and live in another part of the world. In certain cases they had wanted to do so since they were children, either because they had grown up abroad or had been inspired by documentaries and television series. Openness to new personal experiences was described in many other ways, such as curiosity, lust for adventure, and a search for a "spark" in their lives.

Desire for more satisfying work. The nurses and doctors in this study expressed dissatisfaction with Scandinavian health care and their roles in it. They described their work as routine, boring, and without challenges and as something they wanted to escape. They were afraid to become like older colleagues who had gotten "into a rut" and no longer put their heart into their work. The Swedish words kul and rolig were used to describe the participants' expectations and hopes about their humanitarian work. These words can both be translated as "fun." In this context, they clearly meant enjoyable, satisfying, creative, challenging, and exciting.

The work abroad was perceived as an opportunity to assume more responsibility and to think for oneself. Working in another kind of health care system was 
seen as interesting because it would challenge assumptions about "the only way to do something." The volunteers thought that if they became frustrated

\section{The work abroad was perceived as an}

\section{opportunity to assume more responsibility and}

to think for oneself.

with their work in Sweden later in their lives they could do another mission as a "quick fix" for boredom with work and feeling pointless.

\section{Discussion}

The findings of this study reinforce the 2 earlier studies by Anderson and Moore ${ }^{11}$ and Liao-Troth and Dunn. ${ }^{12}$ Common motives among volunteers were to help others, to feel useful and needed, to become self-fulfilled, and to improve the community. This study's findings also support the theories of Hertzberg and Maslow regarding personal development and job satisfaction and indicate the relevance of these theories to the recruitment and selection process within the humanitarian sector.

According to Herzberg, it is the "satisfiers" (e.g., achievement, recognition, the work itself, responsibility, and advancement) that motivate. The findings of this study generally support this theory. The doctors and nurses wanted and expected that the jobs they did during their assignments would make a difference and give them a sense of achievement. They believed that they deserved recognition from their families and the recruiting NGO for their decision to volunteer and for their professional capabilities to carry out the work. They were intensely interested in the work itself and expected it to be challenging, exciting, and stimulating in contrast to their jobs in Swedish health care, which they perceived as boring and routine. They hoped that the assignments abroad would provide more opportunities for taking responsibility.

On the other hand, advancement was not among the findings in this study. The volunteers did not see humanitarian work as something they would continue long enough to move up a career ladder. If they planned to continue working abroad after 1 or 2 humanitarian missions, they thought more in terms of long-term development work.

Dissatisfiers also emerged during the interviews. The volunteers wanted the recruiting NGOs to function well, to have coherent policy, and to provide sufficient field supervision. NGOs were perceived as having potential shortcomings, such as problems with policy or supervision, but these shortcomings did not emerge as major inhibitors for the persons interviewed. Nurses were concerned about feeling cut off from their social circle when they returned home, the risk of serious physical danger in unstable situations, and potential financial hardship resulting from low salaries. All these concerns led to doubts about volunteering. All the participants wanted to develop interpersonal relations as members of a team and maintain relations with friends and family at home. They wanted to have secure working conditions in the field and sufficient salary to maintain their independent lifestyles when they returned.

\section{Maslow has been critized for being too "western" in perspective.}

The findings of this study support Maslow's hierarchy of needs. Persons who have all the lower needs but are not yet self-actualized feel bored and search for something new. In fact, this is how the volunteers described themselves. They lived comfortably in a safe country and had families and social circles. They held professional jobs that were respected by society, and they felt good about their competence. However, they were extremely bored and frustrated and craved an experience that would test their personal limits.

Certain traits of self-actualizing persons identified by Maslow and Heylighen were present in the interviewed volunteers. Heylighen writes, "Perhaps the most striking feature of self-actualizing persons is their openness to experience ... they are eager to undergo new experiences, learn new ideas and skills ...."15 Openness of this sort emerged as a major theme in the findings. The volunteers expressed a desire to try new things, work in other parts of the world, experience other cultures, and have adventures.

Creative problem solving is another trait of selfactualization. "Self-actualizing creativity consists of a general playful attitude towards problem-solving ... which assumes that the conventional way to do it is not necessarily the best way." 15 This attitude was expressed in the volunteers' desire for a chance to work more creatively. They also had negative feelings about the "only one right way" approach they had been taught in the Swedish health care system.

Maslow has been criticized for being too "Western" in perspective. Many traits of self-actualization are individualistic, and individualism is seen as a positive phenomenon in the West. In some cultures, however, being an individual is seen as a lower state than being a worthy member of a social group. ${ }^{15}$ Persons in these cultures who volunteer for humanitarian work may not be motivated by a drive for individual self-actualization. Interviews with local volunteers in recipient countries are needed to give more information.

According to Maslow's theory, people are not concerned about the needs lower in the hierarchy as long as those needs are being sufficiently met. In this study, some volunteers expressed awareness 
and reawakened concern about lower needs when they were faced with the realities of a humanitarian assignment. Learning about danger and the risk of death in the field resulted in concern about safety, especially among the nurses. Similarly, concerns about social needs emerged in connection with fears about becoming restless wanderers or being isolated and alienated when they returned home. Even concern about esteem was expressed in connection with families who did not respect the volunteers' decision to volunteer and recruiting NGOs that did not openly say the volunteers were wanted or did not acknowledge their capabilities.

\section{Implications for the Recruiting Organizations}

Previous research concerning humanitarian aid workers has focused on finding the right persons to fit into existing organizational systems. This study has taken a different approach, analyzing the characteristics, concerns, and expectations of a group of volunteers and, in the process, identifying ways in which the recruiting NGOs can improve procedures and policies.

The interviewing and screening processes used by recruiting NGOs, as well as decisions regarding specific work assignments, should be reconsidered in light of the findings of this study. Recruiting officers should be familiar with Maslow's theory and design their interviews on the assumption that many persons volunteering for humanitarian work are doing so because of a drive toward self-actualization, although they may not express this or even understand their own motivations. Recruiters should realize that many volunteers want to test themselves and find their own limits, which can lead to security risks. Recruiters also should anticipate that potential volunteers, especially nurses, will need reassurance regarding their safety, social, and esteem needs but will be inhibited about seeking that reassurance. The NGO officers should therefore explain clearly how their field security system works, enable communication among volunteers to promote an early sense of community, and make it clear that the accepted volunteers are wanted and valued by the organization.

NGO officers also should have Herzberg's satisfiers and dissatisfiers in mind when evaluating programs and considering changes in priorities. The major satisfier missing from the findings of this study was advancement, which already is a topic of discussion in major humanitarian organizations. Experienced aid workers would like humanitarian work to be recognized as a profession in itself, which would make it easier for them to organize their life between missions and to negotiate salaries.

Attention should also be given to the important dissatisfiers revealed in this study. Specific measures could be identified to help volunteers maintain relationships with their friends and family while they are in the field. Efforts to provide secure working conditions in the field should continue. Salary scales should be re-examined to determine if they are leading to unreasonable financial hardship, especially for nurses, because their financial starting point is lower than that of doctors.

Finally, preparation for the field should include an introduction to the specific organization so that the volunteers feel part of a coherent system. It also should include in-depth education about humanitarian aid work, not just as a practical foundation but as a help for the volunteers' understanding of the immense importance and value of the work for millions of human beings around the world.

\section{References}

1. Spiegel PB. Differences in world responses to natural disasters and complex emergencies. JAMA 2005;293:1915-8.

2. Wheat S. What are NGOs doing here? EU-The Courier 2000;181:55-7.

3. The Action Learning Network for Accountability and Performance in Humanitarian Action (ALNAP). Humanitarian action. Improving performance through improved learning. London: ALNAP; 2002.

4. The Action Learning Network for Accountability and Performance in Humanitarian Action (ALNAP). Humanitarian action. Improving monitoring to enhance accountability and learning. London: ALNAP; 2003.

5. United Nations. Report and summary of main conclusions. Regional workshop on lessons learned and best practices in the response to the Indian Ocean Tsunami; 2005 June 13-14; Medan, Indonesia.

6. Macnair R. Room for improvement. The management and support of relief and development workers. London: Relief and Rehabilitation Network, Overseas Development Institute (ODI); 1995.

7. Kealey DJ. The challenge of international personnel selection. In: Landis D, Bhagat RS, editors. Handbook of intercultural training. 2nd ed. Thousand Oaks (CA): Sage; 1996.

8. Kealey DJ, Protheroe DR. The effectiveness of crosscultural training for expatriates: an assessment of the literature on the issue. Int J Intercultural Relations 1996; 20:141-65.

9. Simmonds S, Gilbert-Miguet P, Siem H, Carballo M, Zeric D. Occupational health of field personnel in complex emergencies: report of a pilot study (report No. WHO/ EHA/98.4). Geneva: World Health Organization/ Environmental Health Agency, UNJMS, ICMH 1998.

10. Henry J. Understanding $\mathrm{HR}$ in the humanitarian sector-a baseline for enhancing quality in management. London: People in Aid; 2004.

11. Anderson JC, Moore LF. The motivation to volunteer. J Voluntary Action Res 1978;7:120-5.

12. Liao-Troth M, Dunn CP. Social constructs and human service: managerial sense making of volunteer motivation. Voluntas 1999;10:345-61.

13. Young B.C. Methods of motivation: yesterday and today (online, 2000, accessed 8 Dec 2005). Available from: URL: http://www.Chaningminds.org

14. Maslow AH. Motivation and personality. New York: Harper and Row; 1970. 
15. Heylighen F. A cognitive-systemic reconstruction of Maslow's theory of self-actualization. Behav Sci 1992;37: 39-57.

16. Gawel JE. Herzberg's theory of motivation and Maslow's hierarchy of needs. Online 1999. Available at http://PAREonline.net/getvn.asp?v=5\&n11. Accessed June 25, 2005.

17. Herzberg F, Mausner B, Snyderman BB. The motivation to work. 2nd ed. New York: John Wiley \& Sons; 1959.
18. Bjerneld M, Lindmark G, Diskett P, Garrett M. Perceptions of work in humanitarian assistance: interviews with returning Swedish health professionals. Disaster Manage Response 2004;2:101-8

19. Granheim UH, Lundman B. Qualitative content analysis in nursing research: concepts, procedures and measures to achieve trustworthiness. Nurse Educ Today 2004; 24:105-12.

\section{Appendix. Illustrative quotations for themes and categories}

\begin{tabular}{|c|c|c|}
\hline Themes & Categories & Illustrative quotations \\
\hline Security & $\begin{array}{l}\text { 1. Concern about low salary } \\
\text { during assignment } \\
\text { 2. Desire for economic secu- } \\
\text { rity upon returning home } \\
\text { 3. Worry about dangers during } \\
\text { the assignment } \\
\text { 4. Wanting the recruiting NGO } \\
\text { to care about their safety } \\
\text { 5. Concern that insecurity } \\
\text { would affect work } \\
\text { performance } \\
\text { 6. Acceptance of insecure } \\
\text { situations } \\
\text { 7. Desire to work for a stable } \\
\text { organization }\end{array}$ & $\begin{array}{l}\text { 1. "I think I will do one or two missions. Then I will not be able to } \\
\text { work more in this field. My savings will be gone." (N1) "It feels } \\
\text { wrong that one must be rich to work as a volunteer." (N1) } \\
\text { 2. "...when I come back, I want to have an apartment that I can } \\
\text { come home to...to close my doors and think about things that } \\
\text { I have been through." (N1) "(I don't want) to move here and } \\
\text { there and live with relatives when I return. It's important that one } \\
\text { has some kind of security." (N1) } \\
\text { 3. "I hadn't realized that my life could be in danger, but I un- } \\
\text { derstand now." (N1) "I don't want to risk my own life." (N1) } \\
\text { "I have become doubtful. It's very dangerous, actually." (N1) } \\
\text { "I hadn't thought of myself with bombs and grenades all around } \\
\text { me." (N1) } \\
\text { 4. "It's important that I feel safe when I go out, that I am taken care } \\
\text { of, that they care about me." (N1) "I think more persons would } \\
\text { dare to go if they felt they could trust the organization. If you } \\
\text { felt they really took care of us." (N1) } \\
\text { 5. "I don't want to go out into a war with weapons, but I can gladly go } \\
\text { out to a place where it is more or less unstable. I think most regions } \\
\text { are more or less unstable." (D1) "It doesn't matter at all where I end } \\
\text { up ...in darkest Iraq or anywhere else. (My) attitude is ... 'it will } \\
\text { work out'." (D1) } \\
\text { 6. "(I don't want to be sent) to the worst refugees situations. At least } \\
\text { not on the first mission, since I feel there are too many new } \\
\text { things I have to learn and have to concentrate on without being } \\
\text { scared." (D1) } \\
\text { 7. "To go out with a relatively stable, established NGO that func- } \\
\text { tions-that feels good." (D2) }\end{array}$ \\
\hline $\begin{array}{l}\text { Community } \\
\text { and } \\
\text { coherence }\end{array}$ & $\begin{array}{l}\text { 1. Looking forward to being } \\
\text { part of a team in the field } \\
\text { 2. Wanting their work to } \\
\text { "make sense" as part of } \\
\text { a larger whole } \\
\text { 3. Visions of a future place in } \\
\text { the humanitarian } \\
\text { community } \\
\text { 4. Fear of feeling socially } \\
\text { alienated upon returning } \\
\text { home } \\
\text { 5. Concern about becoming } \\
\text { rootless and a wanderer }\end{array}$ & $\begin{array}{l}\text { 1. "(I look forward to) team work, to solve problems together." (D1) } \\
\text { "One must be able to...cooperate in the right way...Just that feels } \\
\text { like a major challenge. I think it is important." (D2) } \\
\text { 2. "I can work with anything, as long as I have a sense of coherence } \\
\text { and understand why I am doing what I'm doing...I think it is } \\
\text { important, to be able to manage in a serious way, that you have } \\
\text { a sense of coherence and function." (D2) } \\
\text { 3. "If you've gone out once and been with an organization, then... } \\
\text { you can go to their meetings, keep yourself up-to-date on what is } \\
\text { happening out in the world." (D1) "In the future one can take part } \\
\text { in these kinds of questions." (D1) } \\
\text { 4. "I feel frightened. What will happen when I return? Will everything } \\
\text { feel meaningless?...I don't want to come back into a big black } \\
\text { hole." (N1) } \\
\text { 5. "I don't want to become a restless person, a wanderer who can't } \\
\text { find peace anywhere." (D1) }\end{array}$ \\
\hline
\end{tabular}




\section{Themes \\ Recognition and self- esteem \\ Categories \\ 1. A desire for their families to re- spect their decision to volunteer \\ 2. Wanting the organizations to rec- ognize their abilities \\ 3. Concern that others will not be interested in what they have done \\ 4. Feeling good about their own abilities \\ 5. Wanting to come home feeling more competent}

Professional competence and mastery

Wanting to contribute
1. Confidence in their professional mastery of profession

2. Concern that they may not have certain needed skills

3. Acceptance of their own professional limitations

4. Desire to do work that uses their competence and knowledge

1. Wanting to help others

2. The wish to make a significant impact

3. Trying to justify one's life and pay back society

4. Satisfaction in helping others

5. Perceptions of heroic contributions

6. Feelings about sacrificess

\section{Illustrative quotations}

1. "Most of my relatives don't react as I had thought, 'Oh, how great that you really are doing those things that you've dreamt about,' but exactly the opposite- 'How can you?"' (N2)

2. "I think it is important that you don't have to go there (to the organization) and nag them that you should be allowed to go out on mission, as I've heard happens. Instead, they should say 'we want you'...It gives you a lift. They want me. And I know how to do this. I'm good at it." (D1)

3. "(The lecturer warned us about having) no one to talk with... who understands what we've gone through. He felt it was very difficult." (N1) "In a way one takes it for granted that everyone will be interested in what you have experienced...but it clearly isn't like that." (N1)

4. "To help others makes you feel good." (N2)

5. "I would like to manage to handle some (difficult) situations. I think that will be important, in the future, to remember that I managed with only a stethoscope." (D1)

1. "When I started the course I had butterflies in my stomach...but now I don't. I feel that, yes, I'm going to be able to do this. I feel rather secure about myself." (D2)

2. "It is difficult to know when you have enough professional knowledge to be able to make a contribution." (D1)

3. "You can only do your best. If it isn't sufficient, in any case you've done the best you can." (D1) "The first day, you know nothing....and then one sees, I actually can do this, I can handle this...Then later one goes somewhere else, and there one doesn't know so much, but one handles most of it... there are always new things and one feels that one isn't going to be able to handle this, what shall I do? But one learns." (D1)

4. "When I was at the MSF information meeting. I thought, but good grief, 4 years of university, 8 years of health care experience, why do I need more? Do I really have to go through another 10 weeks education?... But I am very glad now that I've gone through the course. (It) would have been unbelievably naive and stupid (to have) gone out in the field without this special training." (N1)

1. "I strongly feel that I want to go out and contribute." (N1) "My illusion is that there (in the field) I can add something and feel I have an important function." (D1)

2. "To just go out ... and do whatever, it feels like a waste. One wants to go out and do what one knows." (N2) "I'd like the work within my specialty. Then I feel that I can offer something." (D1) "... you want to go out on mission and make a contribution ... (in a humanitarian situation but)... it is just a drop in the Mississippi ... in order to ... make large change, one has to work at a higher level." (N1) "I'd rather work more long-term, in health care projects." (D2)

3. "It's a way of justifying my existence...to help other people is the meaning of life." (N2)

4. "I've got a good life because I was born here. So I want to give something to others." (D1)

5. "I think one has a rather...unrealistic picture of what a contribution will be, or what... one can do. Somewhere in the back of the brain there develops the idea of making a heroic contribution, even if you aren't a hero here at home." (D2) "There was a doctor... who had just been in Sierra Leone....and had operated on about 300 persons during one month... (What he went through) probably wasn't so great ... and not exactly glorious." (N2) "I've been brought down to earth and have somewhat different expectations of myself of what I will do. I don't expect that I will make a heroic contribution." (D2)

6. "You do this (work) as a volunteer. You contribute both your time and your money...everything." (N1) "You sacrifice quite a lot. The risk that something happens when you are away is much greater than if you stayed at home....It is worth it if you feel that what you manage to do is worth the sacrifice. That is the driving force." (D2) 


\begin{tabular}{|c|c|}
\hline \multirow{10}{*}{$\begin{array}{l}\text { Themes } \\
\text { The search } \\
\text { for personal } \\
\text { development } \\
\text { and self- } \\
\text { knowledge }\end{array}$} & Categories \\
\hline & 1. A desire for challenges and \\
\hline & personal development \\
\hline & $\begin{array}{l}\text { 2. Seeking a situation in which they } \\
\text { can test their own limits }\end{array}$ \\
\hline & 3. Extensive "soul searching" about \\
\hline & why they were volunteering \\
\hline & $\begin{array}{l}\text { 4. Looking for situations that "fit" } \\
\text { them, their own "niche" }\end{array}$ \\
\hline & 5. Wanting to know themselves \\
\hline & $\begin{array}{l}\text { better } \\
\text { Seeing the assionment in the }\end{array}$ \\
\hline & context of an overall life plan \\
\hline
\end{tabular}

A search

for new experiences

Desire for more satisfying work

3. Looking for a "kick"
1. Wanting to see the world and other cultures

2. Curiosity and a search for adventure

1. Perception of current jobs as routine and boring

2. Concern about growing "stale" in these jobs

3. Anticipation of humanitarian work as stimulating

4. Desire for more individual responsibility

5. Desire to learn other ways of doing things

6. Seeing future assignments as a quick fix for boredom

\section{Illustrative quotations}

1. "(Our normal work in Sweden) doesn't lead to development, especially not personal development. And I think this kind of work (humanitarian work abroad) would." (N1)

2. "I know that I function extremely well and can handle situations here at home... so I actually want to find my limits somewhere. (Humanitarian work) feels like a bit of... a test." (D2) "How insecure can the situation be before I'm so scared so I can't function effectively?" (D2) "It's extremely interesting to see how you yourself succeed in functioning, how flexible you are when you end up in another culture. You learn rather a lot about yourself." (N2)

3. "One wants to take the opportunity before one becomes old." (N1) "I also don't think that this is a life-time project. Instead, it's something that you do once or twice." (N1) "I feel that now, in the present situation, it works well for me to make a short-term contribution with some kind of catastrophe assistance... when I want to have a family and all that, I want to live abroad, and then I can imagine being involved in a longer-term project." (N2) "I have gone over 1000 times the various arguments for going out in the field. It's hard to put a finger on the reason ... I think it's very hard to explain what drives me." (D1)

4. "(Regarding assignments,) absolutely not in an office. I'd rather be at a clinic. That is me." (D1) "I don't think I could work in a war-torn area. That's not what I had expected. I had thought ... something with women and children. I could make a contribution there instead." (N1) "I will not go out on an emergency assignment, that isn't me. I don't believe that I'd fit in such a situation." (D2)

5. "I think it is hard to know what one is suited for, what one can do." (D2) "How am I going to handle this? What will I do in these situations? It is impossible to answer before one actually goes out. So it is extremely exciting." (D2)

6. "The first time you take food from a buffet table, you take a little of everything, but the second time around, you take what you like the best." (N2)

1. "There is a world out there, that one wants to take part in." (D1) "Since I was a child and saw... the TV-programme "The flying doctors," I have wanted to do the same." (N1)

2. "It is some sort of curiosity which drives you to a big adventure. A joy, a wish to understand other people." (N2)

3. "Most of us want to have a personal 'kick'." (N1)

1. "(One) doesn't want to work in the traditional role and routine." (N1) "It is so very seldom that I do something that I feel is meaningful." (D1) "(The system) takes the joy out of being a doctor. One feels like a machine." (D1)

2. "To do something well, one must have fun. And one wants to do something well. If one doesn't have fun, one gets in a rut. One has seen so many tired senior doctors who have sat doing the same thing for 20 years and wonder what they are doing there." (D1)

3. "I don't think (the work is) fun here. It is certainly more fun abroad than here." (N2) "The farther I am from Sweden, the more fun I think it is. Because there one can be flexible, one can take the resources one has, make plans...make your own mark." (D1) "To be able to do more with less resources, that feels appealing... a challenge." (D2)

4. "(In the field) one uses one brain and doesn't just stand there and do thing by the book." (D1) "(One thing I look forward to is) that you can make use of your ability to think." (D1).

5. "One learns...that everything isn't just as it is in Sweden or as we think it should be either." (N2)

6. "(Someone I talked with at an organization) said that there are many who go out and then come home and work and then they ... travel there for 6 weeks. And when they come back they have left their problems behind. Actually nothing has happened, it hasn't become worse or better, it's just the same. But they can accept it and it feels really fun to come back to work again." (D1) "One can see when one comes home. If everything is meaningless, then one can go out again." (D1) 